BRAVZULIAN JOURNAL

OF MEDICAL AND BIOLOGICAL RESH.ARCH

www.bjournal.com.br
ISSN 0100-879X

Volume 43 (5) 381-496 May 2011

BIOMEDICAL SCIENCES

AND

CLINICAL INVESTIGATION

Braz J Med Biol Res, May 2011, Volume 44(5) 421-427

doi: $10.1590 / \mathrm{S} 0100-879 \times 2011007500039$

Enhanced anti-tumor effect of a gene gun-delivered DNA vaccine encoding the human papillomavirus type 16 oncoproteins genetically fused to the herpes simplex virus glycoprotein D

M.O. Diniz and L.C.S. Ferreira

The Brazilian Journal of Medical and Biological Research is partially financed by

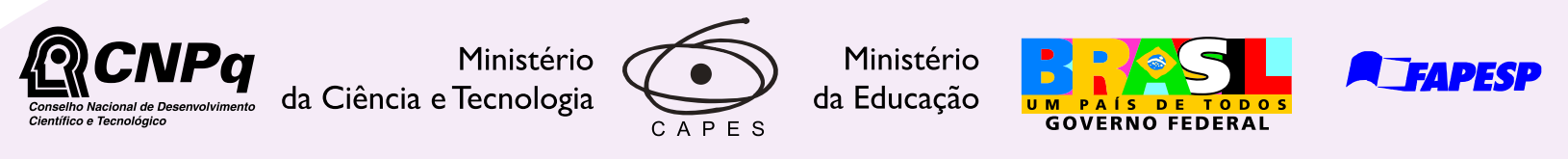

Institutional Sponsors
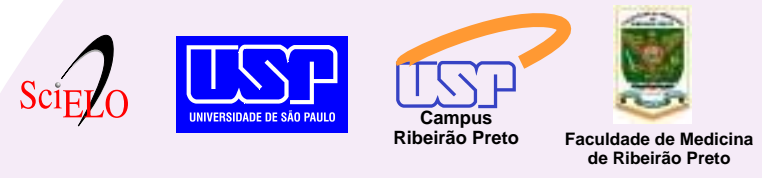
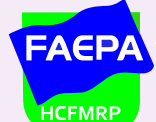

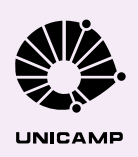

† SHIMADZu

Hotsite of proteomics metabolomics developped by:

GE Healthcare

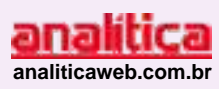

Thermo 


\title{
Enhanced anti-tumor effect of a gene gun-delivered DNA vaccine encoding the human papillomavirus type 16 oncoproteins genetically fused to the herpes simplex virus glycoprotein D
}

\author{
M.O. Diniz and L.C.S. Ferreira
}

Departamento de Microbiologia, Instituto de Ciências Biomédicas, Universidade de São Paulo, São Paulo, SP, Brasil

\begin{abstract}
Anti-cancer DNA vaccines have attracted growing interest as a simple and non-invasive method for both the treatment and prevention of tumors induced by human papillomaviruses. Nonetheless, the low immunogenicity of parenterally administered vaccines, particularly regarding the activation of cytotoxic $\mathrm{CD} 8^{+} \mathrm{T}$ cell responses, suggests that further improvements in both vaccine composition and administration routes are still required. In the present study, we report the immune responses and anti-tumor effects of a DNA vaccine (pgD-E7E6E5) expressing three proteins (E7, E6, and E5) of the human papillomavirus type 16 genetically fused to the glycoprotein $D$ of the human herpes simplex virus type 1 , which was administered to mice by the intradermal $(i d)$ route using a gene gun. A single id dose of pgD-E7E6E5 (2 $\mu \mathrm{g} / \mathrm{dose})$ induced a strong activation of E7specific interferon- $\mathrm{Y}$ (INF- $\mathrm{y}$ )-producing $\mathrm{CD}^{+} \mathrm{T}$ cells and full prophylactic anti-tumor effects in the vaccinated mice. Three vaccine doses inhibited tumor growth in $70 \%$ of the mice with established tumors. In addition, a single vaccine dose consisting of the co-administration of pgD-E7E6E5 and the vector encoding interleukin-12 or granulocyte-macrophage colony-stimulating factor further enhanced the therapeutic anti-tumor effects and conferred protection to 60 and $50 \%$ of the vaccinated mice, respectively. In conclusion, id administration of pgD-E7E6E5 significantly enhanced the immunogenicity and anti-tumor effects of the DNA vaccine, representing a promising administration route for future clinical trials.
\end{abstract}

Key words: Gene gun; DNA vaccine; HPV-16; Anti-cancer vaccine

\section{Introduction}

Cervical cancer is the second leading cause of cancer deaths among women worldwide (1). Human papillomaviruses (HPV) are associated with virtually all cervical cancer cases. The genome of the human papillomavirus type 16 (HPV-16), the most cancer-prone HPV type, is found in at least $50 \%$ of the detected HPV-associated malignancies (2). Currently, two prophylactic anti-HPV vaccines based on virus-like particles (VLPs) are available: Gardasil (VLPs containing the L1 protein from the HPV types 6, 11, 16, and 18) and Cervarix (VLPs containing the L1 protein from the HPV types 16 and 18). Although these vaccines have been shown to be very effective in the generation of neutralizing antibodies, they cannot control existing HPV infections or HPV-associated cellular lesions. Thus, searching for other therapeutic anti-tumor vaccines is a priority that may have an immediate impact on the incidence of HPV-associated tumors.
The control of HPV-associated tumors requires an efficient induction of cellular immune responses, mostly based on antigen-specific CD8 ${ }^{+} \mathrm{T}$ cells. The HPV-16 E6 and $E 7$ oncoproteins, constitutively expressed in cervical tumor cells, are the main target antigens for anti-tumor therapeutic vaccines (3). Recently, DNA vaccines have emerged as a promising approach for inducing effective anti-cancer immunity. Although DNA vaccines may induce strong cellular and humoral responses in murine hosts, the specific immune responses observed in subjects in different clinical trials were usually meager (4). To date, various strategies to improve the immunogenicity of DNA vaccines have been tested, including alternative delivery methods and immunization routes. For instance, the intradermal (id) administration route has been shown to be more efficient than the intramuscular (im) administration route for DNA

Correspondence: M.O. Diniz, Departamento de Microbiologia, ICB, USP, Av. Prof. Lineu Prestes, 1374, 05508-000 São Paulo, SP, Brasil. Fax: +55-11-3091-7354. E-mail: modiniz@usp.br

Received November 4, 2010. Accepted March 10, 2011. Available online April 1, 2011. Published May 16, 2011. 
vaccines in terms of the DNA amount required to achieve a similar antigen-specific immune response (5).

Our group has developed different DNA vaccine vectors encoding the HPV-16 oncoproteins genetically fused with the herpes simplex virus type 1 (HSV-1) gD protein $(6,7)$. The im administration of such DNA vaccines has shown enhanced preventive and therapeutic anti-tumor effects in mice implanted with tumor cells expressing the HPV-16 E7 and E6 oncoproteins. Recently, we reported the development of a DNA vaccine vector (pgD-E7E6E5) encoding three HPV-16 oncoproteins (E7, E6, and E5) with enhanced anticancer effects relative to the previously reported vaccines based on one (E7) or two (E7 and E6) oncoproteins (7). This newly developed vaccine conferred up to $70 \%$ therapeutic anti-tumor protection in mice with established tumor implants after the im administration of three vaccine doses $(100 \mu \mathrm{g}$ DNA/dose). In the present study, we evaluated the anti-tumor effects of the pgD-E7E6E5 vector delivered by id administration using a gene gun. The results showed that the id administration route significantly enhanced the activation of antigen-specific $\mathrm{CD}^{+} \mathrm{T}$ cell responses and the preventive and therapeutic anti-tumor effects of the DNA vaccine.

\section{Material and Methods}

\section{Mice}

Female C57BL/6 mice at 6 to 8 weeks of age were supplied by the Animal Breeding Center of the Biomedical Sciences Institute of the University of São Paulo and were housed at the Parasitology Department of the University of São Paulo. All animal-related procedures were performed according to approved protocols and in accordance with the recommendations for the proper use and care of laboratory animals of the Biomedical Sciences Institute, University of São Paulo.

\section{Cell lines}

The TC-1 cell line was kindly provided by Dr. T.C. Wu (John Hopkins University, Baltimore, MD, USA). These cells were transformed with $\mathrm{V}-\mathrm{HA}$-ras and the $\mathrm{E} 6$ and $\mathrm{E} 7$ genes of HPV-16 (8). The TC-1 cells were cultured in Dulbecco's modified Eagle's medium (DMEM) supplemented with $2 \mathrm{mM}$ L-glutamine, $1 \mathrm{mM}$ sodium pyruvate, $2 \mathrm{mM}$ non-essential amino acids, $10 \mathrm{mM} \mathrm{HEPES} \mathrm{buffer,} 50 \mathrm{U} / \mathrm{mL}$ penicillin/streptomycin, and $10 \%$ fetal bovine serum (FBS) and were kept at $37^{\circ} \mathrm{C}$ at $5 \% \mathrm{CO}_{2}$. Before inoculation, the TC-1 cells were harvested by trypsinization, washed twice, and suspended in serum-free media at $5 \times 10^{6}$ cells $/ \mathrm{mL}$.

\section{DNA vaccines}

The preparation of the DNA vaccines encoding the in tandem fused HPV-16 E7, E6, and E5 oncoproteins (pE7E6E5) or the three oncoproteins genetically fused after the amino acid 244 of the HSV-1 pgD protein (pgD-E7E6E5) has been described (7). The correct in-frame cloning of E7, E6, and E5 encoding genes was confirmed by DNA sequencing. The DNA vaccine (pgD) encoding the complete non-fused HSV-1 gD has been described (6).

\section{Immunization and tumor cell challenge}

Groups of five to ten mice were vaccinated with the DNA vaccines by id administration using a gene gun, through which DNA-coated gold particles ( $1 \mu \mathrm{g}$ DNA/bullet) were delivered to the shaved abdominal region using a heliumdriven device (Biomics, Brazil) with 400 psi charge pressure; each dose contained $2 \mu \mathrm{g}$ DNA. Alternatively, vaccinations were performed by im administration; each dose contained $100 \mu \mathrm{g}$ DNA, divided into two $50-\mu \mathrm{L}$ aliquots and delivered into the tibialis anterior muscle of each hind limb. For the tumor protection experiments, mice were challenged subcutaneously (sc) with $5 \times 10^{5}$ TC- 1 cells suspended in 100 $\mu \mathrm{L}$ serum-free medium; the cells were injected into the left rear flank of the mice 2 weeks after the vaccination. To determine the effect of post-challenge vaccination, mice were vaccinated on the same day $8 \mathrm{~h}$ after being challenged with $5 \times 10^{5} \mathrm{TC}-1$ cells. One or two additional vaccine doses were applied to the animals at weekly intervals thereafter. For the post-challenge experiments with the co-administration of plasmids expressing cytokines, mice were immunized with three doses, each containing $1 \mu \mathrm{g}$ DNA of the vaccine vectors admixed to $1 \mu \mathrm{g}$ DNA of the plasmid expressing interleukin-12 (IL-12) or granulocyte-macrophage colonystimulating factor (GM-CSF). Tumor growth was monitored by visual inspection and palpation three times a week after the challenge. Mice were scored as tumor-bearing when tumors reached a size of approximately 1 to $2 \mathrm{~mm}$ in diameter. Mice were euthanized once tumors exceeded a diameter of $1 \mathrm{~cm}$ and became necrotic or burdensome to the animals. Tumor growth was otherwise followed for a period of 60 days after the challenge.

\section{Intracellular cytokine staining}

Intracellular interferon- $\mathrm{y}$ (IFN- $\mathrm{\gamma}$ ) staining was performed using blood samples treated for $5 \mathrm{~min}$ on ice with the ACK lysing buffer (BioSource International, USA) to rupture red blood cells and then centrifuged at $1000 \mathrm{~g}$ for $5 \mathrm{~min}$. Peripheral blood mononuclear cells (PBMCs) were treated with the lysis buffer again, centrifuged and suspended in DMEM. PBMCs were cultured at the concentration of $10^{6}$ cells/well for $5 \mathrm{~h}$ at $37^{\circ} \mathrm{C}$ in a 96 -well round bottom microtiter plate in $200 \mu \mathrm{L}$ DMEM supplemented with $10 \%$ FBS and $10^{-6} \mathrm{M}$ $\beta$-mercaptoethanol. Brefeldin A (GolgiPlug; BD Bioscience, USA) was added at $1 \mu \mathrm{L} / \mathrm{mL}$. The E7-specific RAHYNIVTF peptide, carrying the immunodominant epitope of E7 for mice of the $\mathrm{H}-2^{\mathrm{b}}$ haplotype (9), or the V3 control peptide, delineated from the sequence of the envelope protein of HIV-1 clade B (VVEDEGCTNLSGF), was used as a stimulus at a concentration of $3 \mu \mathrm{g} / \mathrm{mL}$. After washing, the cells were incubated for $30 \mathrm{~min}$ at $4^{\circ} \mathrm{C}$ with $100 \mu \mathrm{L}$ of a $1: 100$ dilution 
of a fluorescein isothiocyanate (FITC)-conjugated monoclonal antibody to mouse CD8a (BD Bioscience). The cells were washed once with $\mathrm{PBS}$ followed by permeabilization with Cytofix/Cytoperm (BD Bioscience) for $20 \mathrm{~min}$ at $4^{\circ} \mathrm{C}$, washed twice with the Perm/Wash buffer (BD Bioscience) and incubated in the same buffer for $30 \mathrm{~min}$ at $4^{\circ} \mathrm{C}$ with $50 \mu \mathrm{L}$ of a 1:100 dilution of a phycoerythrin (PE)-labeled monoclonal antibody to mouse IFN-Y (BD Bioscience). After washing, the cells were suspended in PBS and were examined by two-color flow cytometry using the FACSCalibur instrument (BD Bioscience). Data were analyzed using the FlowJo software. The percentages of $\mathrm{CD}^{+}$cells positive for IFN-y in all CD8 ${ }^{+} \mathrm{T}$ cells were determined.

\section{Statistical analyses}

Data are reported as means $\pm S D$ and are representatives of at least two independent experiments. Student $t$-test or ANOVA was employed to compare individual data.

\section{Results}

\section{Activation of E7-specific CD8 ${ }^{+} \mathrm{T}$ cell responses and anti-tumor protective effects in mice immunized id with pgD-E7E6E5}

Mice immunized $i d$ with one or two doses of pgD-E7E6E5 $(2 \mu \mathrm{g} / \mathrm{dose})$ developed significant numbers of E7-specific IFN-y-producing CD8 ${ }^{+} T$ cells. Half the mice immunized with one dose of pgD-E7E6E5 developed E7-specific CD8 ${ }^{+} \mathrm{T}$ cell responses, whereas two doses of the vaccine induced positive responses in all vaccinated mice (Figure 1A). Mouse groups immunized with the pgD vector or pE7E6E5 (not fused with the gD protein) did not develop any detectable E7-specific, IFN-y-producing CD8 ${ }^{+} \mathrm{T}$ cell responses.

Although only half the animals immunized with pgD-

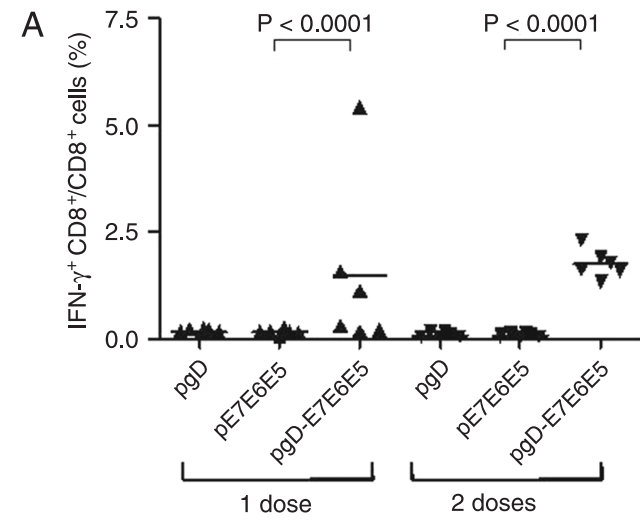

B

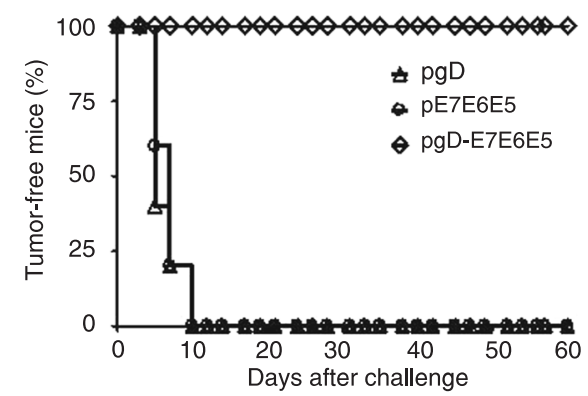

C

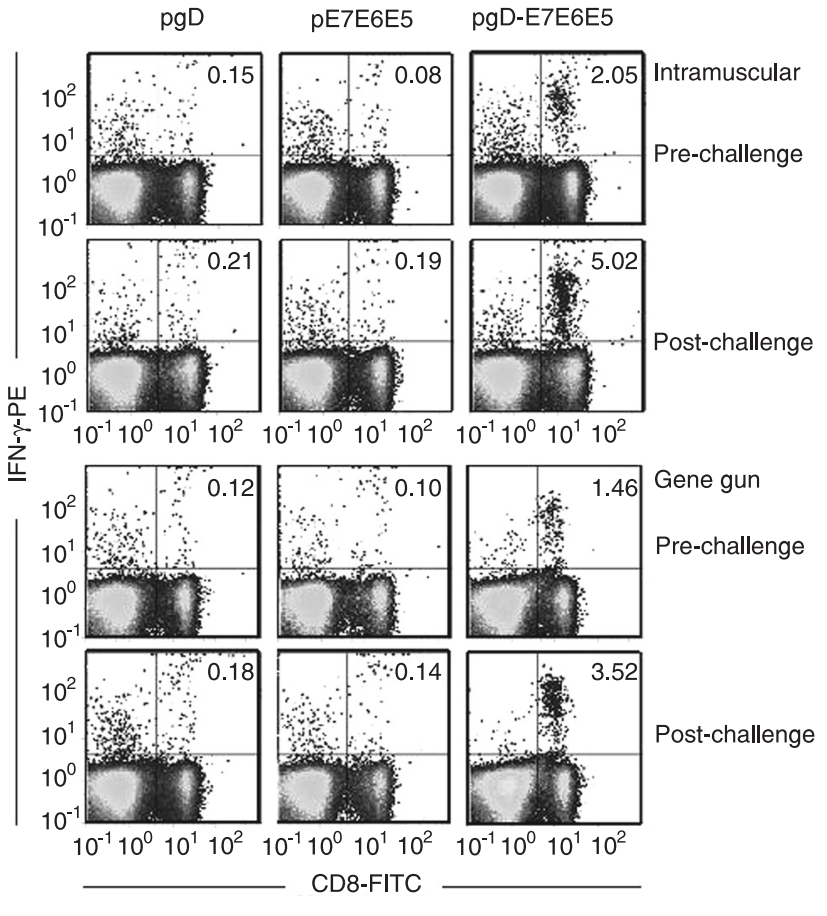

Figure 1. Induction of E7-specific, IFN-y-producing CD8 ${ }^{+} \mathrm{T}$ cell precursors and preventive anti-tumor effects in mice immunized id with the pgD-E7E6E5 vaccine. E7-specific CD8 ${ }^{+} \mathrm{T}$ cells were detected with PBMCs incubated with the synthetic MHC class I-restricted E7 peptide ( ${ }^{49}$ RAHYNIVTF 57$)$ and stained for the CD8 marker (FITC) and accumulated intracellular IFN-y (PE). A, Individual CD8 ${ }^{+}$ $T$ cell responses in mice immunized with one or two doses of pgD, pE7E6E5 or pgD-E7E6E5 delivered with a gene gun (2 $\mu \mathrm{g} / \mathrm{dose})$. The number of E7-specific $C D 8^{+} T$ cells was determined 2 weeks after the last vaccine dose. $B$, Mice immunized with one id dose of pgD-E7E6E5, pE7E6E5, or pgD were challenged with 5.105 TC-1 tumor cells 2 weeks after the last vaccine dose. Tumor growth was followed up to 60 days after inoculation of the TC-1 cells. C, Mice were immunized with one dose of pgD-E7E6E5, pE7E6E5, or pgD delivered via the $i d$ or im route, and the frequencies of E7-specific $C D 8^{+} \mathrm{T}$ cells were determined 2 weeks after the last immunization (pre-challenge) and 2 weeks after the TC-1 challenge (post-challenge) in pooled PBMCs. The numbers at the right upper corners represent the frequencies of E7-specific CD8 ${ }^{+} \mathrm{T}$ cells as a percentage of IFN-y-producing $\mathrm{CD}^{+} \mathrm{T}$ cells of the total detected $\mathrm{CD} 8^{+} \mathrm{T}$ cells. IFN- $\gamma=$ interferon- $\gamma ;$ PE = phycoerythrin; FITC = fluorescein isothiocyanate; PBMCs = peripheral blood mononuclear cells. Statistically significant differences $(P<0.001)$ were noted with regard to mice immunized with pgD or pE7E6E5 control vectors (ANOVA and Turkey test). 
E7E6E5 developed significant anti-E7 $\mathrm{CD}^{+} \mathrm{T}$ cell responses after a single id administration, all vaccinated mice developed full preventive protection against tumor growth after being implanted with TC-1 cells (Figure 1B). The same result was obtained in mice immunized with two id doses of pgD-E7E6E5 (data not shown). No anti-tumor protective effects were observed in mice immunized id with one or two doses of the pgD or pE7E6E5 vectors.

Two weeks after the challenge with TC-1 cells, the number of E7-specific, IFN- $\gamma$-producing $\mathrm{CD}^{+} \mathrm{T}$ cells increased in mice immunized with one dose of pgD-E7E6E5 delivered either by the id $(2 \mu \mathrm{g} /$ dose $)$ or im $(100 \mu \mathrm{g} /$ dose $)$ route (Figure 1C). Collectively, these results demonstrated that the id route significantly enhanced the immunogenicity and anti-tumor effects of the pgD-E7E6E6 vaccine compared to the $i m$ route, which required 50 -fold more DNA to induce similar immune responses.

\section{Therapeutic anti-tumor effects of the id delivered pgD-E7E6E5 vector}

We further investigated the therapeutic anti-tumor effects of pgD-E7E6E5 in mice with established tumors after id administration. One dose of the pgD-E7E6E5 vector did not halt tumor progression (Figure 2A). However, two or three doses conferred 30 and $70 \%$ protection to the mice with established tumors, respectively (Figure 2A). As indicated in Figure 2, mice therapeutically treated with one dose of pgD-E7E6E5 failed to mount a significant E7-specific $\mathrm{CD}^{+}$ $T$ cell response in pooled PBMCs. However, mice treated with two or three doses of pgD-E7E6E5 showed a significant increase in the number of E7-specific $C D 8^{+} T$ cells in a dose-dependent manner, reaching maximum values 20 days after TC-1 cell implantation (Figure 2B). As expected, mice immunized with one, two or three doses of the pgD or pE7E6E5 vectors did not develop anti-tumor or E7-specific

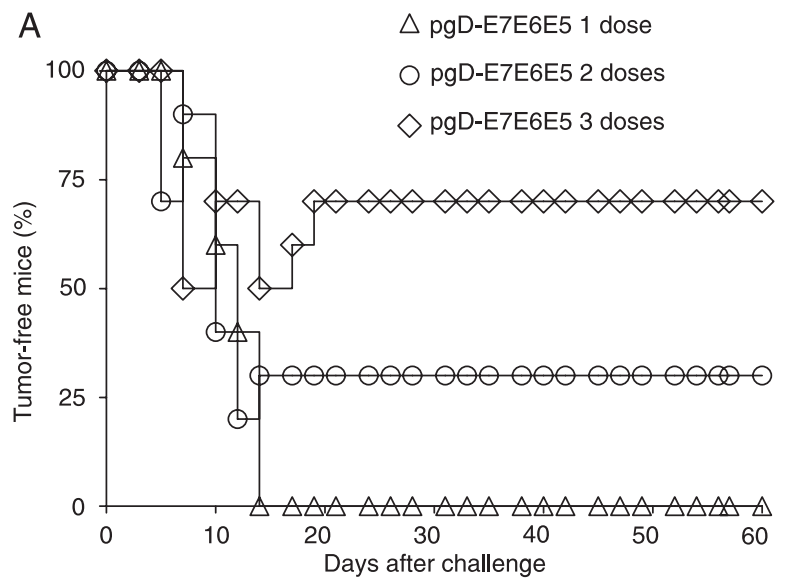

$\mathrm{CD}^{+} \mathrm{T}$ cell responses (data not shown).

Co-administration of the plasmid expressing IL-12 or GM-CSF enhanced the therapeutic anti-tumor effects of im delivered pgD-E7E6E5 (7). Similarly, mice immunized with a single dose of pgD-E7E6E5 and plL-12 (Figure 3A) or pGMCSF (Figure 3B; $2 \mu \mathrm{g} /$ dose) using the gene gun developed 60 and $50 \%$ therapeutic protection against pre-implanted tumor cells, respectively. Under the same conditions, no anti-tumor protection was observed in mice immunized with a single dose of pgD-E7E6E5 (Figure 3). No significant anti-tumor protection was observed in mice immunized with the pIL-12 or pGM-CSF vector (Figure 3).

\section{Discussion}

The immunization route is a critical aspect to evaluate the efficacy of DNA vaccines aiming at clinical applications. In this study, we tested the id immunization route using a gene gun delivering a DNA vaccine expressing three HPV-16 oncoproteins. The results clearly showed that the id administration route required less DNA (compared to the $i m$ route) to achieve a similar antigen-specific $\mathrm{CD}^{+}$ $T$ cell response and, in particular, to achieve prophylactic and therapeutic anti-tumor effects. Specifically, the present findings showed that a 50 -fold reduction in the DNA amount injected by the id route preserved the same immunogenicity and anti-tumor effects observed in mice immunized by the im route (7). Considering that most DNA vaccines tested under clinical conditions showed lower immunogenicity compared to that under experimental conditions, the possibility of improving the performance of DNA vaccines by changing the administration route represents a significant improvement in the development of therapeutic vaccines targeting HPV-associated tumors.

Previous studies have shown that the administration

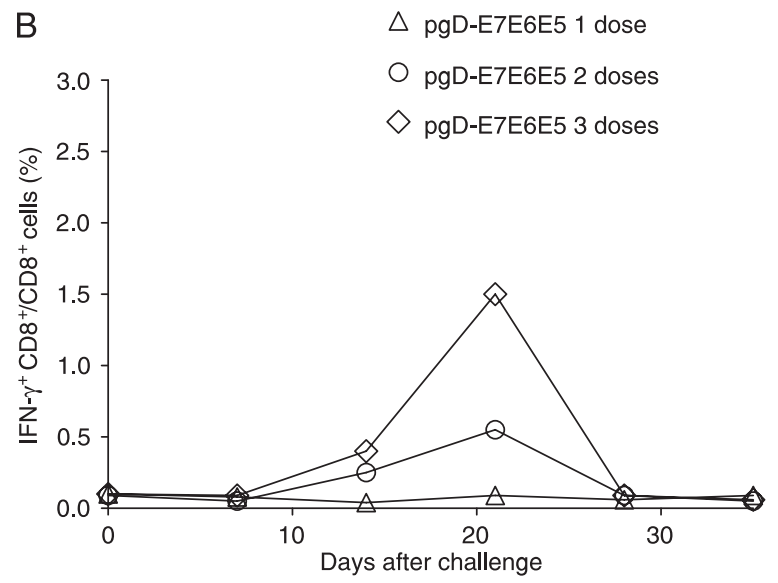

Figure 2. Therapeutic anti-tumor effects and E7-specific $\mathrm{CD} 8^{+} \mathrm{T}$ cell responses in mice immunized id with pgD-E7E6E5. $A$, Therapeutic anti-tumor effects in mice previously inoculated with TC-1 cells and immunized with one, two or three doses of pgD-E7E6E5 administered with a gene gun. $B$, Detection of E7-specific CD8 ${ }^{+} T$ cells in pooled PBMCs from mice inoculated with TC- 1 tumor cells and immunized with one, two or three doses of pgD-E7E6E5 delivered via the id route. 

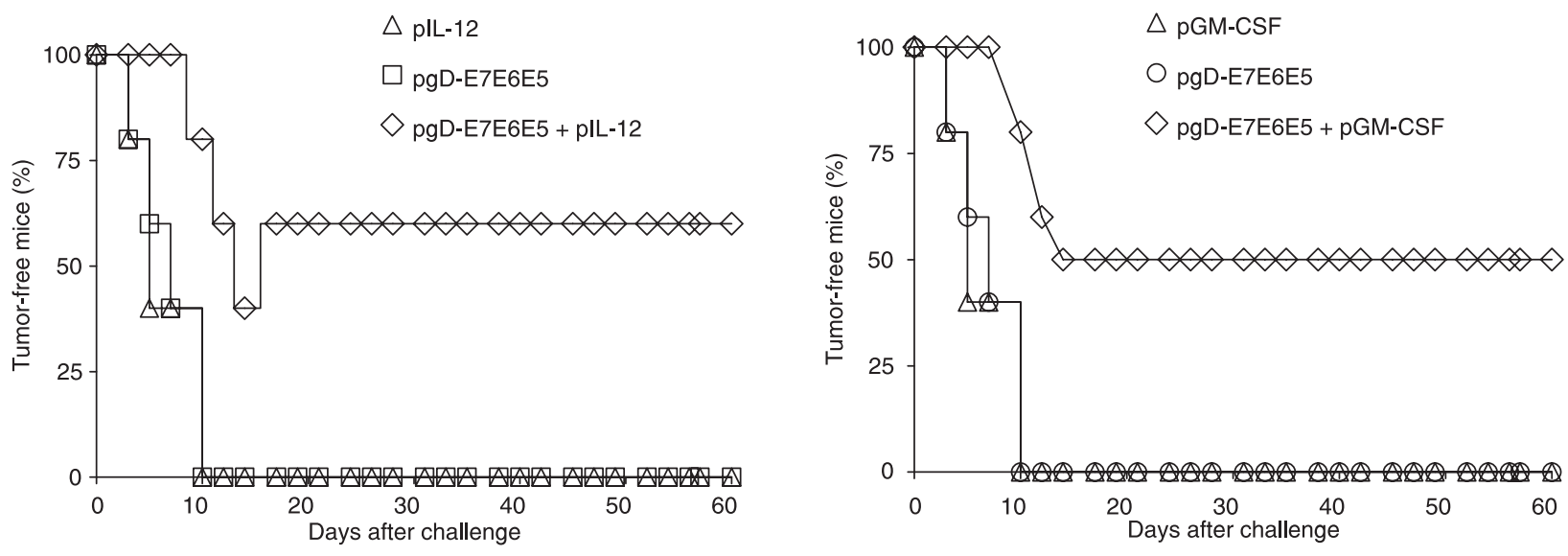

Figure 3. Co-administration of pgD-E7E6E5 and IL-12 or GM-CSF-encoding plasmids confers enhanced anti-tumor therapeutic effects. Mice were immunized id with a single dose of pgD-E7E6E5 admixed with plL-12 (A) or pGM-CSF (B) vectors (1 $\mu \mathrm{g} / \mathrm{dose}$ of each vector). Mice immunized with a single dose of the pgD-E7E6E5, plL-12 or pGM-CSF are also indicated. The vaccines were administered $8 \mathrm{~h}$ after inoculation of $5 \times 10^{5}$ TC-1 cells. IL-12 = interleukin-12; GM-CSF = granulocyte-macrophage colony-stimulating factor.

route may have a significant impact, both quantitatively and qualitatively, on the immune responses elicited in vaccinated mice. In particular, DNA vaccines administered by the id route have been reported to elicit Th2-biased immune responses, whereas administration by the im route preferentially induces a Th1-biased immune response (10-15). In contrast to other DNA vaccines, our results demonstrated that the id administration of the pgD-E7E6E5 vector did not change the pattern of immune response elicited in vaccinated mice when compared to the im administration. These results indicate that the immunization route should be evaluated for each DNA vaccine construct regarding the activation of specific immune responses to the encoded antigen because features other than the administration route might affect the immunogenicity of the DNA, such as the encoded antigen itself, the animal's genetic background and the vector backbone.

A comparative study conducted by Trimble et al. (16) used needle $\mathrm{im}$, biojector and gene gun immunization of a DNA vaccine expressing E7 from HPV-16 fused to Mycobacterium tuberculosis heat shock protein 70 . The authors observed that gene gun immunization induced the highest number of antigen-specific $\mathrm{CD} 8^{+} \mathrm{T}$ cells and slightly better anti-tumor effects against TC-1 tumors. Our study showed similar results. Although no statistically significant differences in the numbers of E7-specific IFN-y-producing $\mathrm{CD}^{+} \mathrm{T}$ cells or in anti-tumor effects were detected in mice submitted to the two immunization routes, the amount of DNA used in the gene gun immunization was 50 -fold less. Taken together, these results indicate that the id administration route can significantly improve the performance of DNA vaccines encoding HPV-16 oncoproteins.

The better performance of DNA vaccines delivered with a gene gun for inducing cell-mediated immunity can be attributed to the cell types involved in antigen processing and presentation. The id route preferentially favors the stimulation of epidermal keratinocytes as well as professional antigen-presenting cells (APCs) such as Langerhans cells $(17,18)$. The higher numbers of activated APCs in epidermal keratinocytes relative to those in muscular tissue, where cross-priming prevails, probably at least partially contribute to the enhanced activation of major histocompatibility complex class I-restricted cytotoxic T lymphocytes (19-21).

Cytokines or chemokines simultaneously delivered with DNA vaccines as plasmids or purified proteins have been shown to increase Ag-induced immune responses or to alter the Th1:Th2 balance (22-28). Significantly higher therapeutic anti-tumor protection levels were observed after id immunization with a single dose of pgD-E7E6E5 co-administered with the plasmid expressing IL-12 or GMCSF. Treatment with IL-12 DNA has been shown to enhance antigen-specific cell-mediated immunity and to promote anti-tumor activity in different animal models $(28,29)$. The ability of IL-12 to augment antigen-specific immunity is related to the induction of a Th1-biased immune response, leading to the enhanced activation of cytotoxic T lymphocyte responses (30-32). GM-CSF has been successfully used to increase the immune responses to antigens encoded by DNA vaccines $(33,34)$. GM-CSF has been reported to initiate the proliferation, differentiation, and activation of macrophages, neutrophils, and various APCs (35-39).

The present study demonstrates that the id delivered pgD-E7E6E5 vector can generate strong antigen-specific $\mathrm{CD}^{+} \mathrm{T}$ cell responses in vaccinated mice and confer enhanced anti-tumor protection with much lower DNA loads when compared to the im delivered DNA vaccine. These results will contribute to the design of therapeutic DNA vaccines against HPV-associated tumors for clinical applications. 


\section{References}

1. Pisani P, Parkin DM, Bray F, Ferlay J. Estimates of the worldwide mortality from 25 cancers in 1990. Int J Cancer 1999; 83: 18-29.

2. Bosch FX, Manos MM, Munoz N, Sherman M, Jansen AM, Peto J, et al. Prevalence of human papillomavirus in cervical cancer: a worldwide perspective. International biological study on cervical cancer (IBSCC) Study Group. J Natl Cancer Inst 1995; 87: 796-802.

3. Eiben GL, da Silva DM, Fausch SC, Le Poole I, Nishimura MI, Kast WM. Cervical cancer vaccines: recent advances in HPV research. Viral Immunol 2003; 16: 111-121.

4. Kutzler MA, Weiner DB. DNA vaccines: ready for prime time? Nat Rev Genet 2008; 9: 776-788.

5. Donnelly JJ, Wahren B, Liu MA. DNA vaccines: progress and challenges. J Immunol 2005; 175: 633-639.

6. Lasaro MO, Diniz MO, Reyes-Sandoval A, Ertl HC, Ferreira LC. Anti-tumor DNA vaccines based on the expression of human papillomavirus-16 E6/E7 oncoproteins genetically fused with the glycoprotein $D$ from herpes simplex virus-1. Microbes Infect 2005; 7: 1541-1550.

7. Diniz MO, Lasaro MO, Ertl HC, Ferreira LC. Immune responses and therapeutic antitumor effects of an experimental DNA vaccine encoding human papillomavirus type 16 oncoproteins genetically fused to herpesvirus glycoprotein D. Clin Vaccine Immunol 2010; 17: 1576-1583.

8. Lin KY, Guarnieri FG, Staveley-O'Carroll KF, Levitsky HI, August JT, Pardoll DM, et al. Treatment of established tumors with a novel vaccine that enhances major histocompatibility class II presentation of tumor antigen. Cancer Res 1996; 56: 21-26.

9. Feltkamp MC, Smits HL, Vierboom MP, Minnaar RP, de Jongh BM, Drijfhout JW, et al. Vaccination with cytotoxic $T$ lymphocyte epitope-containing peptide protects against a tumor induced by human papillomavirus type 16-transformed cells. Eur J Immunol 1993; 23: 2242-2249.

10. Gramzinski RA, Millan CL, Obaldia N, Hoffman SL, Davis HL. Immune response to a hepatitis B DNA vaccine in Aotus monkeys: a comparison of vaccine formulation, route, and method of administration. Mol Med 1998; 4: 109-118.

11. Kasinrerk W, Moonsom S, Chawansuntati K. Production of antibodies by single DNA immunization: comparison of various immunization routes. Hybrid Hybridomics 2002; 21: 287-293.

12. Lima KM, dos Santos SA, Santos RR, Brandao IT, Rodrigues JM Jr, Silva CL. Efficacy of DNA-hsp65 vaccination for tuberculosis varies with method of DNA introduction in vivo. Vaccine 2003; 22: 49-56.

13. Hu H, Lu X, Tao L, Bai B, Zhang Z, Chen Y, et al. Induction of specific immune responses by severe acute respiratory syndrome coronavirus spike DNA vaccine with or without interleukin-2 immunization using different vaccination routes in mice. Clin Vaccine Immunol 2007; 14: 894-901.

14. Pokorna D, Rubio I, Muller M. DNA-vaccination via tattooing induces stronger humoral and cellular immune responses than intramuscular delivery supported by molecular adjuvants. Genet Vaccines Ther 2008; 6: 4.

15. Hu H, Huang X, Tao L, Huang Y, Cui BA, Wang H. Comparative analysis of the immunogenicity of SARS-CoV nucleocapsid DNA vaccine administrated with different routes in mouse model. Vaccine 2009; 27: 1758-1763.

16. Trimble C, Lin CT, Hung CF, Pai S, Juang J, He L, et al. Comparison of the CD8+ T cell responses and antitumor effects generated by DNA vaccine administered through gene gun, biojector, and syringe. Vaccine 2003; 21: 4036-4042.

17. Gaffal E, Schweichel D, Tormo D, Steitz J, Lenz J, BasnerTschakarjan E. Comparative evaluation of CD8+CTL responses following gene gun immunization targeting the skin with intracutaneous injection of antigen-transduced dendritic cells. Eur J Cell Biol 2007; 86: 817-826.

18. Hung CF, Monie A, Alvarez RD, Wu TC. DNA vaccines for cervical cancer: from bench to bedside. Exp Mol Med 2007; 39: 679-689.

19. Fu TM, Ulmer JB, Caulfield MJ, Deck RR, Friedman A, Wang $S$, et al. Priming of cytotoxic T lymphocytes by DNA vaccines: requirement for professional antigen presenting cells and evidence for antigen transfer from myocytes. Mol Med 1997; 3: 362-371.

20. Iwasaki A, Torres CA, Ohashi PS, Robinson HL, Barber $\mathrm{BH}$. The dominant role of bone marrow-derived cells in CTL induction following plasmid DNA immunization at different sites. J Immunol 1997; 159: 11-14.

21. Corr M, Lee DJ, Carson DA, Tighe $\mathrm{H}$. Gene vaccination with naked plasmid DNA: mechanism of CTL priming. J Exp Med 1996; 184: 1555-1560.

22. Calarota SA, Weiner DB. Enhancement of human immunodeficiency virus type 1-DNA vaccine potency through incorporation of T-helper 1 molecular adjuvants. Immunol Rev 2004; 199: 84-99.

23. Moore AC, Kong WP, Chakrabarti BK, Nabel GJ. Effects of antigen and genetic adjuvants on immune responses to human immunodeficiency virus DNA vaccines in mice. $J$ Virol 2002; 76: 243-250.

24. Tsuji T, Hamajima K, Ishii N, Aoki I, Fukushima J, Xin KQ, et al. Immunomodulatory effects of a plasmid expressing B7-2 on human immunodeficiency virus-1-specific cell-mediated immunity induced by a plasmid encoding the viral antigen. Eur J Immunol 1997; 27: 782-787.

25. Okada E, Sasaki S, Ishii N, Aoki I, Yasuda T, Nishioka K, et al. Intranasal immunization of a DNA vaccine with IL12- and granulocyte-macrophage colony-stimulating factor (GM-CSF)-expressing plasmids in liposomes induces strong mucosal and cell-mediated immune responses against HIV1 antigens. J Immunol 1997; 159: 3638-3647.

26. Kim JJ, Bagarazzi ML, Trivedi N, Hu Y, Kazahaya K, Wilson $\mathrm{DM}$, et al. Engineering of in vivo immune responses to DNA immunization via codelivery of costimulatory molecule genes. Nat Biotechnol 1997; 15: 641-646.

27. Scott P. IL-12: initiation cytokine for cell-mediated immunity. Science 1993; 260: 496-497.

28. Tsuji T, Hamajima K, Fukushima J, Xin KQ, Ishii N, Aoki I, et al. Enhancement of cell-mediated immunity against HIV-1 induced by coinnoculation of plasmid-encoded HIV-1 antigen with plasmid expressing IL-12. J Immunol 1997; 158: 4008-4013.

29. Mazzolini G, Prieto J, Melero I. Gene therapy of cancer with interleukin-12. Curr Pharm Des 2003; 9: 1981-1991.

30. Hsieh CS, Macatonia SE, Tripp CS, Wolf SF, O'Garra A, Murphy KM. Development of TH1 CD4+ T cells through 
IL-12 produced by Listeria-induced macrophages. Science 1993; 260: 547-549.

31. Manetti R, Gerosa F, Giudizi MG, Biagiotti R, Parronchi $P$, Piccinni MP, et al. Interleukin 12 induces stable priming for interferon gamma (IFN-gamma) production during differentiation of human Thelper (Th) cells and transient IFN-gamma production in established Th2 cell clones. J Exp Med 1994; 179: 1273-1283.

32. Tsung K, Meko JB, Peplinski GR, Tsung YL, Norton JA. IL-12 induces T helper 1-directed antitumor response. J Immunol 1997; 158: 3359-3365.

33. Staff C, Mozaffari F, Haller BK, Wahren B, Liljefors M. A Phase I safety study of plasmid DNA immunization targeting carcinoembryonic antigen in colorectal cancer patients. Vaccine 2010 (in press).

34. Rollman E, Hinkula J, Arteaga J, Zuber B, Kjerrstrom A, Liu $\mathrm{M}$, et al. Multi-subtype gp160 DNA immunization induces broadly neutralizing anti-HIV antibodies. Gene Ther 2004; 11: 1146-1154.

35. Kitamura T, Hayashida K, Sakamaki K, Yokota T, Arai K, Miyajima A. Reconstitution of functional receptors for hu- man granulocyte/macrophage colony-stimulating factor (GM-CSF): evidence that the protein encoded by the AIC2B CDNA is a subunit of the murine GM-CSF receptor. Proc Natl Acad Sci U S A 1991; 88: 5082-5086.

36. Wakimoto H, Abe J, Tsunoda R, Aoyagi M, Hirakawa K, Hamada $\mathrm{H}$. Intensified antitumor immunity by a cancer vaccine that produces granulocyte-macrophage colonystimulating factor plus interleukin 4. Cancer Res 1996; 56: 1828-1833.

37. Jager E, Ringhoffer M, Dienes HP, Arand M, Karbach J, Jager D, et al. Granulocyte-macrophage-colony-stimulating factor enhances immune responses to melanoma-associated peptides in vivo. Int J Cancer 1996; 67: 54-62.

38. Jones T, Stern A, Lin R. Potential role of granulocyte-macrophage colony-stimulating factor as vaccine adjuvant. Eur J Clin Microbiol Infect Dis 1994; 13 (Suppl 2): S47-S53.

39. Disis ML, Bernhard H, Shiota FM, Hand SL, Gralow JR, Huseby ES, et al. Granulocyte-macrophage colony-stimulating factor: an effective adjuvant for protein and peptidebased vaccines. Blood 1996; 88: 202-210. 